Authors' opinion

\title{
Is it time for transition from the subject-based to the integrated preclinical medical curriculum?
}

\author{
Marina Yu. Kapitonova ${ }^{1}$, Sergey P. Gupalo ${ }^{2}$, Sergey S. Dydykin ${ }^{3}$, Yury L. Vasil'ev ${ }^{3}$, Viktor B. Mandrikov ${ }^{4}$, \\ Sergey V. Klauchek ${ }^{4}$, Olga V. Fedorova ${ }^{4}$ \\ ${ }^{1}$ UNIMAS, Kota Samarahan, Sarawak, Malaysia. \\ ${ }^{2}$ UNISZA, Kuala Terengganu, Terengganu, Malaysia. \\ ${ }^{3}$ Sechenov University, Moscow, Russia. \\ ${ }^{4}$ Volgograd State Medical University, Volgograd, Russia.
}

Received 22 May 2020, Accepted 28 May 2020

(C) 2020, Kapitonova M.Yu., Gupalo S.P., Dydykin S.S., Vasil'ev Yu.L., Mandrikov V.B., Klauchek S.V., Fedorova O.V.

(C) 2020, Russian Open Medical Journal

\begin{abstract}
In the 60 s of the last century, a number of new universities in the world began to apply an integrated program of medical education, the cornerstone of which was problem-oriented education. Thus, the Flexner model of higher education adopted by that time in most countries of the world, with its characteristic segregation of teaching of the theoretical and clinical disciplines, which had ceased to satisfy the needs of modern healthcare, was gradually replaced by a new system that put the student in the center of the educational process and opened the way to active methods of teaching being focused on the end result - training of graduates whose qualifications most fully satisfy the needs of society.

Over the half-century history of its existence, this system has been adopted by most medical universities in different countries of the world, in many of which it has undergone significant modifications in accordance with the needs of national educational standards. Many medical universities in Russia and other countries of the former Soviet Union showed interest in this system, some of the medical faculties of our country accepted certain elements of it. However, up to date no integrated preclinical medical education program has been applied in any of the Russian universities. Hereby we are undertaking an attempt to analyze the reasons and assess the possible perspectives for the transition of medical universities in Russia to teaching of fundamental and biomedical disciplines using the integrated curriculum.
\end{abstract}

Keywords: integrated curriculum, medical education.

Cite as Kapitonova MYu, Gupalo SP, Dydykin SS, Vasil'ev YuL, Mandrikov VB, Klauchek SV, Fedorova OV. Is it time for transition from the subject-based to the integrated preclinical medical curriculum? Russian Open Medical Journal 2020; 9: e0213.

Correspondence to Sergey P. Gupalo. Address: Faculty of Medicine, UNISZA, Kuala Terengganu, Terengganu 21300, Malaysia. Phone: +60176205710.

\section{Introduction}

The rapid development of medical knowledge and changing conditions for the functioning of the national health care system dictate the need to review existing medical educational programs. When the medical curriculum is becoming more and more applied, preclinical departments have to look for more flexible approaches to teaching of their disciplines in accordance to the needs of clinical departments and the requirements of practical health care to make medical education outcome-based from the very first day of its implementation. For a long time, medical education was focused on the acquisition of professional knowledge and skills, while currently this approach may no longer be considered sufficient, as modern graduates also require an ability to communicate, collaborate, develop logical constructions and obtain the skills to do research and conduct scientific discussions. In various universities in the world, these aspects are integrated into the goals of educational programs [1-3].

The Flexner's reform of medical education, launched at the beginning of the $20^{\text {th }}$ century, suggested a disciplinary model of teaching in preclinical years of medical curriculum, after which the students passed exams in fundamental and biomedical subjects and only then they went on to study clinical medicine. Despite the positive features of Flexner's reform, such as enhanced requirements to the proficiency of applicants, utilization of scientific achievements in medical education, teaching of clinical medicine at the patient's bedside, this model soon began to impede further development of medical curriculum due to its strictly unified standard, passive teaching methods, fragmentation and isolation of knowledge obtained in preclinical departments, focus on hospital medicine rather than a healthcare system that would satisfy the needs of modern society [4-6].

From the late 60 -ies - beginning of the 70 -ies of the last century, problem-based learning and an integrated medical curriculum were started at the medical faculties of the newly established universities, such as McMaster University in Canada and University of New Castle in Australia $[1,7,8]$. The decisive role in the success of these truly revolutionary transformations that began to unveil in the medical education was played by two outstanding medical teachers: John Hamilton, who headed the committee on medical education, and Howard Barrows, the founder of problem-based learning at McMaster University. 
The innovations in the aforesaid medical universities began with the restructuring of preclinical education: from subjectoriented to integrated, with all its currently well-known attributes: problem-based learning, an objective structured clinical examination (OSCE) using simulation technologies, summative and formative assessment of knowledge and skills, organization of the educational process around the most significant tasks that students must be able to solve successfully upon graduation $[1,3$, 9].

As described by John Hamilton [7], integration itself at that time was not a major objective, but since problem-based learning was launched [10], the consolidation of preclinical disciplines to solve biomedical problems became inevitable. The reform of medical education, which started at McMaster University, was picked up by many medical schools in the world, as its attractiveness was primarily due to the fact that it put the student in the center of the educational process, trained him as a person who can solve the medical problems of modern society. If in the Flexner model of medical education preclinical students did not see the relevance of the obtained theoretical knowledge to their future clinical practice or saw it in a very truncated form, thereafter the integrated program started to teach students to think like real doctors from their first day at the medical university [1]. Thus, graduates of medical universities who had adopted an integrated program were better prepared to meet the needs of the society they were supposed to serve to. The integrated curriculum was recognized as the best way to build up competencies, and it received a great support of the national accreditation agencies [6, 13-15].

\section{Material and Methods}

This review paper is based on the materials collected from the data bases: PubMed, SCOPUS, Web of Science, Google Scholar, elibrary, and personal long-term experience of the authors in teaching of integrated and discipline-based preclinical medical curriculum.

\section{Results}

\section{"Horizontal" and "vertical" integration in medical curriculum}

Vertical integration strengthens the link between preclinical education and the clinical phase of the medical university program. At the same time, the preclinical phase becomes more focused on clinical practice, and the clinical phase becomes more structured and more frequently addresses the preclinical disciplines in different ways. The preclinical phase includes a discussion of clinical cases in problem-based learning and an acquisition of practical skills in simulation centers. The ethical, humanistic and populational aspects of medicine and healthcare are included in the vertical axis using active teaching methods and problem-based teaching in small groups [1, 2].

The experience of most medical universities in the world shows that the transition to an integrated program requires a significant investment of resources and time of teachers and involves serious psychological and pedagogical transformations; however, multiple scientific studies in the field of medical education have repeatedly demonstrated the advantage of an integrated teaching of preclinical medicine over traditional mode. Numerous achievements in the field of medical education have shown that an integrated curriculum promotes deeper assimilation of the program and, most importantly, better survival of knowledge and stronger confidence of the students in their competencies [3, 16-18].

The fundamental difference between the integrated and traditional program, based on practically isolated study of individual biomedical disciplines, is the presence in the former of a "horizontal firmware" and a fine synchronization of the content taught by preclinical disciplines, such as anatomy, physiology, biochemistry, pathology, microbiology, pharmacology, public health. This "firmware" differs from quite common formal coordination of the programs taught in medical schools, as the former requires that the content of the disciplines in the integrated program is very tightly synchronized in the time-table, coordinated and subordinated to the main goal - adequate preparation of students for the clinical exposure and development of their clinical thinking "Horizontal" integration with the development of interdisciplinary modules allows to identify "gaps" and redundancies in the teaching content of preclinical disciplines, to do the "mapping" of the topics taught to ensure the quality of construction of the educational ladder, whether it is based on the study of systems or diseases/pathological conditions. To provide greater "rigidity" to the whole "construction" the necessary attribute of an integrated program - problem-based learning - is introduced, which is demonstrating growing importance and increasing its share in preclinical medical education up to 16 hours a week in a number of western universities $[9,19]$.

Problem-based learning is a logical step in the development of students' ability to synthesize and integrate theoretical concepts into clinical medicine. Harvard University almost completely reoriented its $1^{\text {st }}$ year program to this mode of training, which had an extremely positive impact on the educational process, although there are potentially broad areas for its improvement and finer tuning. The competency-based approach has also become one of the integral attributes of an integrated program that "sews through" the interdisciplinary blocks/modules from which the preclinical program is built with its educational objectives and assessment tools $[5,13,20]$.

In the framework of integrated curriculum, preclinical disciplines pay particular attention to the clinical relevance of the teaching material with the introduction of active teaching methods, development of critical thinking, communicational skills and other professional competencies among the students.

Problem-based learning, widely implemented throughout the world, is designed to support all these educational goals and objectives, although some resource-saving methodologies, such as case- or team-based learning, involving 40-95 students, are also applied in the integrated curriculum or even more often - in a hybrid program; these methodologies also contributes to the integration of fundamental and biomedical disciplines among themselves [21].

In the 80 -ies, the SPICES strategy gained a great popularity [12], according to which the medical education program should become student-centered, problem-oriented, integrated, societyoriented, elective and systematic as opposed to a teacheroriented, based on the collection of information, based on the study of individual disciplines, hospital-oriented, unified and based on the principles of mentoring (student-centered/teachercentered, problem-based/information-gathering, integrated/discipline-based, community-based/hospital-based, elective/ uniform and systematic/apprenticeship-based). 
At that time, in the 80 -ies, the second model was prevailing in the established medical universities, and only new universities took a liberty of selecting the path of "SPICES" strategy, while since the mid-90-ies more and more universities have chosen the innovative path refusing the Flexner's dogma $[22,23]$.

\section{Assessment of knowledge and skills in an integrated program}

The integrated curriculum has changed approaches to assessment of student knowledge, whereby great importance is given to the self-evaluation of students, and a formative assessment rather than a summative one. The introduction of an integrated program based on systems approach has led to the widespread adoption of progress tests and quizzes for each organ system. In many universities, traditional subject-based exams were taken over by the integrated exams with different types of assignments, various modifications of the tests, such as multiplechoice questions (MCQs), single answer questions (SAQs), single best answer questions (SBAQ), objective structured practical examination (OSPE), problem-based questions(PBQ), modified essay questions (MEQ), etc. These tests contain the components of several disciplines and are assessed with a final grade, contributed by scores from all assignments of all the contributing disciplines. At the same time, teachers of each discipline have an opportunity to gain a complete cross-section of the grades in all types of tests of their subject and analyze the teaching outcomes or learning difficulties of students in each topic [24-26].

\section{The spread of the integrated medical programs in the world}

The integrated medical curriculum has a very extensive geography. Starting in English-speaking countries (Canada and Australia), its most important attribute - problem-oriented learning - quickly spread to the USA, Europe (Netherlands, Great Britain, Germany, France, Spain, Switzerland, Norway, etc.), New Zealand, countries of Asia and Africa (India, Japan, China, Malaysia, Indonesia, South Africa, etc.). In some countries, mainly Englishspeaking, they spread reasonably quickly and smoothly, confidently gaining the support of national educational agencies. In contrast, in other countries, such as Germany, Spain, and Japan, the transition was much slower, in stages, and not too quickly overcoming the inertness of the post-Flexner system $[6,14,17,23$, 27-34]. One of the advantages for some universities was the fact that the integrated curriculum allows to maintain a large number of students with fewer teachers, without compromising the quality of education $[4,14]$.

\section{Integrated program options}

Different countries and universities have applied various models of the integrated curriculum: with or without problembased learning, with emphasis on the "central core" of the program, with construction of the educational spiral of the "learning ladder" using multi-, inter- and transdisciplinary integration. In a number of universities in different countries, the transition to an integrated program occurs through an intermediate stage - a "hybrid" program, which is a combination of the features of a subject-based and integrated curriculum. Integration options, among others, include the integration of clinical and preclinical disciplines in advanced courses, as well as multidisciplinary lectures on clinical topics with the involvement of specialists from fundamental departments (anatomists, pathologists, etc.). These approaches are very valuable and have proven effectiveness, and they can be considered intermediate steps towards the full horizontal integration of the medical educational program $[13,22]$.

It should be noted that the UMS (Unified Methodological System) of I. M. Sechenov First Moscow State Medical University, was developed in the 70 -ies of the $20^{\text {th }}$ century by a creative team under the leadership of the first vice-rector, professor I.A. Sychenikov, which was successfully applied until the beginning of the $21^{\text {st }}$ century. The UMS included the following main components: an activity approach, an invariant approach in the educational process, a systematic approach, a program-targeted approach, a modular and competency-based approach, and was a typical "hybrid" program that represented a combination of features of an discipline-based and integrated curriculum [35].

Along with the traditional "module" system, in which preclinical subjects are integrated into in system-based courses, the "spiral model" is gaining more and more popularity, in which there is horizontal and vertical integration, and revision of the material studied previously at a higher level [13, 15, 34].

\section{Evaluation of the integrated curriculum}

Different methods were used to assess the quality of the curriculum by parallel comparison of the level of training in a traditional and integrated curriculum, including involvement of independent evaluators, various questionnaires for students and teachers on the perception of their learning/teaching as a part of an integrated program $[6,17,36]$. There was no evidence of a declined quality of education due to introduction of an integrated curriculum. However, the impact of the Flexner Report on medical education has been so strong that some universities still adhere to non-integrated teacher-centered models of training with few sessions of active learning [14]. However, it should be noted that a large number of medical educators believe that in the modern world the quality of higher education as a whole is declining. Thus a world-renowned educator E.D. Hirsch [37] criticized a current reform of higher for its emphasis on the acquisition by students of skills for self- learning in the rapidly changing circumstances of the modern life, while the quality of knowledge itself continues to deteriorate. Some Russian researchers share this point of view [38, 39].

According to some educators, the primary goal of the modern educational reform is obviously to occupy a leadership position in education and dictate its own conditions to the rest of the world [39]. A successful reform should be based on a clearly formulated national idea, reflecting the ideological ambitions of the countries and universities, and balancing between globalization and cultural autonomy with a pronounced national identity. Past experience of many countries showed that there are different scenarios of further development: from full collapse of the traditional institutions to smooth transformation of the training system with a special consideration of the existing educational environment. The passionate desire of local educational officials and administrators "to do better" according to a western or any another model causes a big concern among professional teachers who are critically evaluating the outcomes of even most advanced innovations. The history of the "Bologna process" is a vivid example thereof, and we believe that the upcoming transition of the Russian medical universities form a traditional to an integrated curriculum of preclinical disciplines should start as a pilot project in several 
universities, followed by a transparent evaluation of the consequences.

The end of the last century was marked by the transition of many medical universities in the world to an integrated curriculum for teaching of biomedical disciplines. Furthermore, the intent of medical educators to introduce and further improve preclinical integrated medical curriculum is going stronger, as evidenced by the snowball of publications in the medical literature: more than twenty seven thousand references in the PUBMED database refer to the "medical education" combined with "integrated curriculum". At the same time, publications from the countries of the former Soviet Union are sporadic and are absent in Russian journals of this database.

\section{An integrated program in Russia and the post-soviet countries}

In medical universities of several countries of the former Soviet Union, primarily such as Kazakhstan, Uzbekistan and Kyrgyzstan, the concept of an integrated medical curriculum is being actively developed. However, in most cases integration takes place at the preclinical-clinical program level, while the biomedical departments still teach their disciplines traditionally.

Kazakhstan has developed a roadmap for the project "Modernisation of Medical Education and Science" of the Ministry of Health of the Republic of Kazakhstan in 2018. Interdisciplinary classes are held at a number of universities, such as biochemistrypathology integrated lectures [40]. The integration of the curriculum and restructuring of the university programs emphasizes competency-based approach in every teaching/learning module [41]. However, problem-based learning which is a cornerstone of the integrated curriculum is introduced in a number of universities only after the $2^{\text {nd }}$ year of training [42].

In our opinion, introduction of an integrated medical curriculum is most successfully implemented at the Karaganda State Medical University, which has been applying a module-based teaching model for the last ten years, delivering interdisciplinary lectures, introducing problem-oriented teaching technologies, conducting integrated exams and an OSCE, recommending interdisciplinary textbooks and creating their own packages for problem-based learning. At the same time, they are successfully using experience of other countries with a long-standing practice of integrated educational technologies. However, the integrated curriculum has been introduced by them starting only from the $3^{\text {rd }}$ year of training, while in the preclinical years a traditional disciplinary-based approach is maintained. Among the reasons listed as restraining factors from the transition to the integrated medical curriculum the educationists state a strict discipline-based approach to the program construction, tough existing educational standards with predetermined teaching-learning load, as well as discipline-based assessment methods of student performance during examinations which contradict to the logistics of the integrated program $[41,43,44]$.

In the Russian universities, the idea of integration in medical education is not new. For decades, medical universities in our country have strived for maximal "vertical" integration of preclinical and clinical disciplines, using multidisciplinary "crosstalking" programs for teaching of the main clinical subjects, to which all biomedical disciplines should contribute [45]. However, the idea of "horizontal" integration of the departments teaching fundamental subjects is relatively young. At the same time, integrated curriculum of the preclinical medical education is gaining increased interest in the Russian medical educational environment, as evidenced by hot discussions on this issue among educators at the major scientific events on the preclinical disciplines, such as the $13^{\text {th }}$ and $14^{\text {th }}$ congresses of the International Morphological Association, etc. The issue turns to become particularly important after cancellation of internships at medical universities of the Russian Federation, which triggers growing significance of clinically relevant integrated medical curriculum [27].

In the Russian scientific medical literature, there are many examples of a deep comprehension of the needs of transition to the integrated preclinical curriculum in its various aspects, such as development of educational and methodological complexes of modular training, search for the new evaluation tools in the context of interdisciplinary integration; understanding of the importance of mutual influence and interconnection of the contents of various academic disciplines in order to develop a comprehensive, interrelated and holistic system of scientific competencies in the students, the introduction of problemoriented education [46]. While the majority of Russian medical educators consider "vertical" integration in medical curriculum to be acceptable, there is no consensus among them in terms of "horizontal" integration: some lecturers consider development of close interdisciplinary connections to be essential [45], others believe that integration of in preclinical years is not necessary, and the traditional disciplinary approach should be maintained in teaching of the biomedical subjects [47].

It is worth noting that term "problem-based learning" among the teaching staff of biomedical departments is not always properly used to designate a particular teaching method proposed by G. Barrows [10], while different types of problem-based questions and assignments applied by individual disciplines may not be considered as a "problem-based learning". Several departments introduced new teaching methods, contributing to the optimisation of the educational process, such as delivery of the problem-based lectures, employing problem-based situations, in which students are taught to think, solve problems, apply their theoretical knowledge gained in practice. However, these methods may not be named "problem-based learning", as they lack an interdisciplinary approach which implies participation of the majority or even all of the preclinical departments. This substitution of concepts may cause misunderstanding and hamper introduction of traditional problem-based education in such an educational environment. The faculties intending to introduce problem-based learning should avoid another "growth disease", such as application of multidisciplinary problem-solving packages individually by one department, and especially by the lecturers without certain expertise. Such an approach may be detrimental for the educational environment, since problem-based technology is multidisciplinary, and requires skills acquired through specialised training.

Paradoxically, so far no Russian university ever tried to introduce an integrated curriculum with problem-based learning even at the level of pilot projects, despite the great desire of modern medical teachers to participate in this most promising form of current preclinical medical education.

Trial workshops on problem-oriented education in the Russian Federation showed that students highly appreciate this method of training, want to participate in it, and state an increased 
motivation to study theoretical disciplines. At the same time, Russian students participating in the master classes successfully coped with the part of the assignment, which required knowledge in theoretical disciplines in which they had recently passed the exams (anatomy, histology), but were much worse oriented in the part of the assignment, where it was required to apply knowledge in subjects that they continue to study (biochemistry, physiology). Moreover, compared to the students who are trained in an integrated medical curriculum, they were less confident when application of common sense was required to solve the problem, and demonstrated lower level of collateral thinking. One of the main tasks of problem-based learning is to develop in students the appropriate communicational skills and ability to perform teamwork, which were lower in the Year 2 medical students trained in the traditional preclinical program compared to their peers trained in the integrated curriculum. Problem-based learning is a good tool to motivate the students to strive to lead, share resources, maintain dynamics of group discussions, comply with communicative ethical standards which are hardly addressed in the traditional preclinical teaching.

Among the reasons hindering the introduction of an integrated curriculum and problem-based learning is a high teaching load of the Russian lecturers of bio-medical disciplines, tight framework of educational programs recommended by the higher educational authorities, lack of resources shared by the separate departments.

\section{Discussion}

In spite of all difficulties, some important prerequisites for the transition from traditional to integrated teaching have recently emerged in the Russian universities. One of them is an introduction of the Moodle platform in many Russian medical schools, which opens the way to "blended" education (online and face-to-face), which undoubtedly contributes to the enhanced student-teacher integration and strengthens collaboration between the lecturers of different disciplines. Furthermore, it can be the first step towards real interdisciplinary integration, when the lecturers are able not only to appreciate the sequence of teaching modules but also get a deeper view into the content taught in the "neighbouring" departments and see all the inconsistencies, redundancies and sometimes contradictions in approaches to various scientific problems, which are inevitable among the representatives of various disciplines (anatomists, histologists, physiologists, etc.), but should be minimised in educational programs.

The second necessary prerequisite for the transition to an integrated curriculum is an establishment of the medical education units in several medical universities of the Russian Federation, which over time have a good chance to develop into medical education departments able to consolidate preclinical disciplines on the way to this transition. Established medical education departments with professionally trained staff may lead the process of integration and serve as a useful platform for the biomedical disciplines to coordinate their programs in promoting higher level of readiness of students to the clinical training and combining problem-based learning with early clinical exposure.

The third prerequisite for the transition to an integrated program is an establishment of the successful pre-university programs in several Russian medical universities, which can significantly re-format the Year 1 curriculum of the medical and pediatric faculties in the nearest future; this may pave the way to the higher flexibility of the teaching programs; at the same time, it would release capacity for the problem-based learning and other attributes of the integrated curriculum, which are being practiced in the increasing number of the universities all over the world.

\section{Conclusion}

Currently, Russia has all the prerequisites necessary for the transition of medical universities to an integrated curriculum of preclinical medical education.

\section{Conflict of interest}

We declare no conflict of interest for this work.

\section{References}

1. Quintero GA, Vergel J, Arredondo $M$, Ariza $M C$, Gómez $P$, PinzonBarrios AM. Integrated Medical Curriculum: Advantages and Disadvantages. J Med Educ Curric Dev 2016;3: JMECD.S18920. https://doi.org/10.4137/JMECD.S18920.

2. Wijnen-Meijer M, Gartmeier M, Berberat PO. Overview on research in the field of medical education. HNO 2020; 68(4): 231-237. https://doi.org/10.1007/s00106-019-00790-3.

3. Chen J, Zhou J, Wang Y, Qi G, Xia C, Mo G, et al. Blended learning in basic medical laboratory courses improves medical students' abilities in self-learning, understanding, and problem solving. Adv Physiol Educ 2020; 44(1): 9-14. https://doi.org/10.1152/advan.00076.2019.

4. Finnerty EP, Chauvin S, Bonaminio G, Andrews M, Carroll RG, Pangaro LN. Flexner revisited: the role and value of the basic sciences in medical education. Acad Med 2010; 85(2): 349-355. https://doi.org/10.1097/acm.0b013e3181c88b09.

5. Gutierrez CM, Cox SM, Dalrymple JL. The Revolution in Medical Education. Tex Med 2016; 112(2): 58-61. https://pubmed.ncbi.nlm.nih.gov/26859376.

6. Vashe A, Devi V, Rao R, Abraham RR, Pallath V, Umakanth S. Using an integrated teaching approach to facilitate student achievement of the learning outcomes in a preclinical medical curriculum in India. Adv Physiol Educ 2019; 43(4): https://doi.org/10.1152/advan.00067.2019.

7. Hamilton JD. The McMaster curriculum: a critique. $\mathrm{Br}$ Med J 1976; 1(6019): 1191-1196. https://doi.org/10.1136/bmj.1.6019.1191.

8. Harden RM. Approaches to curriculum planning. Med Educ 1986; 20(5): 458-466. https://doi.org/10.1111/j.1365-2923.1986.tb01193.x.

9. Neville AJ, Norman GR. PBL in the Undergraduate MD Program at McMaster University: Three Iterations in Three Decades. Acad Med 2007; 82(4): 370-374. https://doi.org/10.1097/acm.0b013e318033385d.

10. Barrows HS. Problem-based learning in medicine. MD program, Faculty of Medicine, McMaster University. Hamilton, Ontario: McMaster University education monograph, 1973.

11. Barrows HS. Problem-solving learning. Med Educ 1980; 14(3): 242-243. https://doi.org/10.1111/i.1365-2923.1980.tb02266.x

12. Harden RM, Sowden S, Dunn WR. Educational Strategies in Curriculum Development: The SPICES Model. Med Educ 1984; 18(4): 284-297. https://doi.org/10.1111/j.1365-2923.1984.tb01024.x.

13. Brauer DG, Ferguson KJ. The integrated curriculum in medical education: AMEE Guide No. 96. Med Teach 2015; 37(4): 312-322. https://doi.org/10.3109/0142159X.2014.970998.

14. González-Soltero R, Learte AIR, Sánchez AM, Gal B. Work station learning activities: a flexible and scalable instrument for integrating across basic subjects in biomedical education. BMC Med Educ 2017; 17(1): 236. https://doi.org/10.1186/s12909-017-1084-z.

15. Fraser $S$, Wright $A D$, van Donkelaar $P$, Smirl JD. Cross-sectional comparison of spiral versus block integrated curriculums in preparing 
medical students to diagnose and manage concussions. BMC Med EduC 2019; 19(1): 17. https://doi.org/10.1186/s12909-018-1439-0.

16. Haramati A. Educating the Educators: A Key to Curricular Integration. Acad Med 2015; 90(2): 133-135. https://doi.org/10.1097/acm.0000000000000444.

17. Gustin MP, Abbiati M, Bonvin R, Gerbase MW, Baroffio A. Integrated problem-based learning versus lectures: a path analysis modelling of the relationships between educational context and learning approaches. Med Educ Online 2018; 23(1): 1489690. https://doi.org/10.1080/10872981.2018.1489690.

18. Dominguez I, Zumwalt AC. Integrating the basic sciences in medical curricula: focus on the basic scientists. Adv Physiol Educ 2020; 44(2): 119-123. https://doi.org/10.1152/advan.00172.2019.

19. Gullo C, Dzwonek B, Miller B. A Disease-Based Approach to the Vertical and Horizontal Integration of a Medical Curriculum. Med Sci Educ 2016; 26(1): 93-103. https://doi.org/10.1007/s40670-015-0208-5.

20. Chang BJ. Problem-based learning in medical school: A student's perspective. Ann Med Surg (Lond) 2016; 12: 88-89. https://doi.org/10.1016/j.amsu.2016.11.011.

21. Bowe CM, Voss J, Thomas Aretz $\mathrm{H}$. Case method teaching: an effective approach to integrate the basic and clinical sciences in the preclinical medical curriculum. Med Teach 2009; 31(9): 834-841. https://doi.org/10.1080/01421590902922904.

22. Harden RM. The integration ladder: a tool for curriculum planning and evaluation. Med Educ 2000; 34(7): 551-557. https://doi.org/10.1046/j.1365-2923.2000.00697.x.

23. Davis MH., Harden RM. Planning and implementing an undergraduate medical curriculum: the lessons learned. Med Teach 2003; 25(6): 596608. https://doi.org/10.1080/0142159032000144383.

24. Daniels VJ, Pugh D. Twelve tips for developing an OSCE that measures what you want. Med Teach 2018; 40(12): 1208-1213. https://doi.org/10.1080/0142159x.2017.1390214.

25. Garg A, Mulloy KB. Developing a Problem-Based Learning Approach to the Integration of Environmental and Occupational Health Topics Into Medical School Curriculum. J Occup Environ Med 2018; 60(08): 754759. https://doi.org/10.1097/jom.0000000000001325.

26. Tweed M. The Interaction of Correctness of and Certainty in MCQ Responses. Med Teach 2018; 40(5): 535. https://doi.org/10.1080/0142159X.2017.1396309.

27. Falck G. Self-reported level of practical skills after the revision of a medical school curriculum in Trondheim. Tidsskr Nor Laegeforen 2003; 123(16): 2268-2270. Norwegian. https://pubmed.ncbi.nlm.nih.gov/14508551.

28. Onishi H. History of Japanese Medical Education. Korean J Med Educ 2018; 30(4): 283-294. https://pubmed.ncbi.nlm.nih.gov/30522257.

29. Kasper J, Greene JA, Farmer PE, Jones DS. All Health Is Global Health, All Medicine Is Social Medicine: Integrating the Social Sciences Into the Preclinical Curriculum. Acad Med 2016; 91(5): 628-632. https://doi.org/10.1097/acm.0000000000001054.

30. Wang $Q$, Li $H$, Pang $W$, Liang $S$, Su Y. Developing an integrated framework of problem-based learning and coaching psychology for medical education: a participatory research. BMC Med Educ 2016; 16: 2. https://doi.org/10.1186/s12909-015-0516-x.

31. Hiatt RA, Engmann NJ, Ahmed M, Amarsi Y, Macharia WM, Macfarlane SB, et al. Population Health Science: A Core Element of Health Science Education in Sub-Saharan Africa. Acad Med 2017; 92(4); 462-467. https://doi.org/10.1097/acm.0000000000001320.

32. Ravikirti, Sharma S. Undergraduate Medical Teaching: Time to integrate? J Assoc Physicians India 2018; 66(8): 85-86. https://pubmed.ncbi.nlm.nih.gov/31324092.

33. Kiessling C, Rotthoff T, Schnabel KP, Stosch C, Begenau J. 20 years of model curricula in German-speaking countries. GMS J Med Educ 2019; 36(5): Doc65. https://doi.org/10.3205/zma001273.
34. Rheingans A, Soulos A, Mohr S, Meyer J, Guse AH. The Hamburg integrated medical degree program iMED. GMS J Med Educ 2019; 36(5): Doc52. https://doi.org/10.3205/zma001260.

35. Belogurova VA. Scientific organization of educational process: Handout for universities, 4th ed. Moscow - St. Peterburg: Nestor-Istoria, 2014 619 p. Russian. https://search.rsl.ru/ru/record/01007508321.

36. Thompson KL, Gendreau JL, Strickling JE, Young HE. Cadaveric dissection in relation to problem-based learning case sequencing: $A$ report of medical student musculoskeletal examination performances and self-confidence. Anat Sci Educ 2019; 12(6): 619-626. https://doi.org/10.1002/ase.1891.

37. Hirsch ED. Why knowledge matters: rescuing our children from failed educational theories. Harvard: Harvard Education Press, 2016; 280 p. https://www.hepg.org/hep-home/books/why-knowledge-matters\#.

38. Verbitsky AA. Teacher as a main subject of the educational reform. Higher Education in Russia 2014; (4): 13-20. Russian. https://doi.org/10.24412/FhChkPXA1R0.

39. Klimova SM. Higher education reform: "own" and "aliens". Vestnik Rossijskoj Akademii Nauk 2015; 85(1): 57-61. Russian. https://doi.org/10.7868/S0869587315010065.

40. Smailova ZK, Olzhaeva RR, Alimbaeva AR, Murtazina DD, Sydykova KT, Sovetov BS, et al. To the question of teaching basic disciplines in light of the modernization of medical education. Science \& Healthcare 2018; 20(5): 176-183. Russian. https://doi.org/10.24412/FhCOD4mJCVY.

41. Dosmagambetova RS, Nursultanova SD. Organization and improving integrated learning strategies. In: Republican Scientific-Practical Conference "Integrated Learning: Status and Development Trends". Karaganda, Kazakhstan: Publishing House of Karaganda State Medical University, 2011: 32-35. Russian. https://issuu.com/gulden 7/docs/integrirovannoe obuchenie.

42. Zhakupbekova MO. Perception and motivation of 5th-year students ("General Medicine") when completing cases based on medical errors. In: Abstracts IX All-Russian Conference with international participation "Week of Medical Education - 2018", Proceedings Collection (Moscow, May 15-17, 2018). Moscow, Russia: Publishing House of the First Moscow State Medical University named after I.M. Sechenov, 2018: 48. Russian. http://www.medobrconf.ru/userfiles/ufiles/theses Med 01-06.pdf.

43. Dosmagambetova RS, Riklefs IM, Riklefs VP, Bukeeva AS, Muratova AZ, Kalieva ShS, et al. Features of medical education in Kazakhstan. Medical education and professional development 2014; 18(4): 75-85. Russian. https://doi.org/10.24412/FhCl4yXycFU.

44. Bakirova RYe, Nursultanova SD, Tusupbekova KT. Improvement strategy of integrated training in the credit system. Medicine and Ecology 2016; (3(80)): 153-155. Russian. https://doi.org/10.24412/FhCbhScit 8

45. Nikolaenko YV. Speciality competency standards and integrated education. In: Abstracts $X$ All-Russian Conference with the international participation "Week of Medical Education - 2019", Proceedings Collection (Moscow, April 1-5,2019). Moscow, Russia: Publishing House of the First Moscow State Medical University named after I.M. Sechenov, 2019: 6. Russian. http://www.medobrconf.ru/userfiles/ufiles/theses_site_2019.pdf.

46. Pshennikova EV, Borisova NV, Malogulova IS. Interdisciplinary integration within the modular education in a Medical Institute. Vestnik of NEFU, Series 'Medical Sciences' 2017; (1(06)): 38-45 Russian. https://doi.org/10.24412/FhCxFdq9H10.

47. Popkov VM, Protopopov AA, Kloktunova NA. Innovation and conservatism: a contradiction or incentive for the development of national higher medical education. Accreditation in Education 2012, (1(53)): 67. Russian. https://www.elibrary.ru/item.asp?id=19408053. 
Authors:

Marina Yu. Kapitonova - MD, PhD, Professor of Anatomy, Faculty of Medicine and Health Sciences, UNIMAS, Kota Samarahan, Sarawak, Malaysia. https://orcid.org/0000-0001-6055-3123.

Sergey P. Gupalo - MD, MSc, Associate Professor of Pathology, Faculty of Medicine, UNISZA, Kuala Terengganu, Teregganu, Malaysia. https://orcid.org/0000-0003-3376-1431.

Sergey S. Dydykin - MD, PhD, Professor, Head of the Department of Operative Surgery and Topographical Anatomy, Sechenov University, Moscow, Russia. https://orcid.org/0000-0002-1273-0356.

Yury L. Vasil'ev - MD, PhD, Associate Professor, Department of Operative Surgery and Topographical Anatomy, Sechenov University, Moscow, Russia. https://orcid.org/0000-0003-3541-6068.

Viktor B. Mandrikov - PhD, Professor, Head of the Department of Physical Culture and Health, Volgograd State Medical University, Volgograd, Russia. https://orcid.org/0000-0003-1970-7527.

Sergey V. Klauchek - MD, PhD, Professor, Head of the Department of Normal Physiology, Volgograd State Medical University, Volgograd, Russia. https://orcid.org/0000-0003-2206-1894.

Olga V. Fedorova - MD, PhD, Associate Professor, Department of Histology, Embryology and Cytology, Volgograd State Medical University, Volgograd, Russia. https://orcid.org/0000-0003-0481-9155. 